\title{
CEPAL Review marks its fortieth anniversary
}

The first issue of CEPAL Review was published in the first half of 1976. Forty years have now passed since that inaugural edition, under Raúl Prebisch's direction, burst onto the academic debate on the development of Latin America and the Caribbean, with novel and heterodox approaches to different facets of, and policies for addressing the region's problems. These have been four decades of fruitful work which aimed to portray, as accurately as possible, the historical reality of each stage in the development process, together with the structural complexities, the specific conjunctures, and the emergence of new national, regional and global phenomena involved in this process.

During these 40 years, CEPAL Review has published over a thousand articles, opening its pages to contributions from the most distinguished economists, sociologists, political scientists and academics from Latin America and farther afield, affiliated to the main specialized agencies in the economic, societal and environmental areas of development.

CEPAL Review has brought to light a collection of 118 regular issues, with corresponding versions in English and Spanish. The collection also includes five special editions, including the 1998 issue commemorating the fiftieth anniversary of the Economic Commission for Latin America and the Caribbean (ECLAC), two issues in French (2005 and 2010), one in Portuguese (2010) and one in Mandarin Chinese (2012).

Our journal has served as a vital tool for spreading the key ideas conceived within the academic debate as a contribution to regional development. Such has been the case since its earliest articles on the nature of peripheral capitalism and the styles of development during the 1970s — written by Prebisch and Aníbal Pinto (the Review's second editor), respectively - followed by the critical examination of the environmental impacts of such styles, the debt crisis and the "lost decade" of the 1980s, and the dissemination of ideas relating to changing production patterns with social equity and neostructuralist reformulations since the 1990s, which have continued under an approach of equality and inclusive development in the present decade.

Issue number 95, published in August 2008, marked the inclusion of CEPAL Review in the Social Sciences Citation Index (SSCI) published by Thomson Reuters, which stands out as one of the milestones of Oscar Altimir's tenure as editor. This landmark achievement has enriched the Review's pool of contributing authors, its editorial line and its impact, leading to its becoming one of the most frequently cited journals in academic publications within the region. The eight-year editorship of André Hofman, who has now taken retirement after almost 30 years of dedicated service to ECLAC, saw the establishment of an Editorial Board, consisting of renowned specialists in development issues from Latin America and the Caribbean and other world regions. This period has been especially fruitful for us, as CEPAL Review has ventured into new subject areas, such as the recent international financial crises, inequality and its many faces, global warming, the care economy and gender issues in the development process, among others. Our geographical coverage has also expanded with the inclusion of new analyses, especially with regard to the development of Andean and Caribbean economies.

This special edition of CEPAL Review, commemorating our fortieth anniversary, provides a perfect example of a thematic and geographical collage, and deals with many of the aforementioned topics. The editorial team wishes to take this opportunity to thank Alicia Bárcena, Executive Secretary of ECLAC, for her steadfast support for our efforts. Likewise, we wish to share this rich and satisfying editorial experience with our readers, renewing our commitment to raising new contributions on development problems in Latin America and the Caribbean, with academic independence and, in this manner, firmly committed to our content policy and editorial quality standards.
Miguel TorRes

Technical Editor

CEPAL Review
Osvaldo Sunkel

Chairman of the Editorial Board

CEPAL Review 